\title{
Medium- and short-term channel and island evolution in a disturbed gravel bed river (Brenta River, Italy)
}

\author{
Johnny Moretto, ${ }^{1}$ Emanuel Rigon, ${ }^{1}$ Luca Mao, ${ }^{2}$ Lorenzo Picco, ${ }^{1}$ Fabio Delai, ${ }^{1}$ \\ Mario Aristide Lenzi ${ }^{1}$
}

\author{
1Department of Land, Environment, Agriculture and Forestry, University of Padova, Padova, Italy; \\ ${ }^{2}$ Department of Ecosystems and Environment, Pontificia Universidad Católica de Chile, \\ Santiago, Chile
}

\begin{abstract}
The timing and extent of the morphological and island changes that have occurred in the last thirty years in a gravel bed river that has been heavily impacted by human activities were analysed by nine sets of aerial photographs, repeated topographical measurements and morphological-vegetation surveys. Dam operations and gravel mining activities have produced modifications in the natural sediment regime that have generated important morphological responses in the channel. Large areas of the formerly active channel were colonised by riparian forest, both as islands and as marginal woodlands. The cessation of gravel extraction in the late 1990s seems to be causing incipient reversion of this pattern, with evidence of vegetation erosion/channel widening. Alteration of sediment regime has played a major role in the medium- and short-term channel evolution. However, only relevant flood events (recurrence interval $>10$ years) appear to determine substantial island erosion and, therefore, the proportion of islands versus channel fluctuates depending on flood history. Smaller scale analysis (sub-reach level) was more effective in describing morphological responses and relationships with the sediment dynamics within the 20 $\mathrm{km}$ study reach.
\end{abstract}

Correspondence: Mario Aristide Lenzi, Department of Land, Environment, Agriculture and Forestry, University of Padova, Padova, Italy.

E-mail: marioaristide.lenzi@unipd.it

Key words: channel and island dynamics, human impact, floods, gravel bed river, Italy.

Acknowledgements: this research has been carried out within the framework of the University of Padova Projects CARIPARO, Linking geomorphologic processes and vegetation dynamics in gravel-bed rivers and the UNIPD Strategic Project GEORISKS, geological, morphological and hydrological processes: monitoring, modelling and impact in North-Eastern Italy, Research Unit STPD08RWBY-004.

Received for publication: 27 November 2012.

Accepted for publication: 1 March 2013.

(OCopyright J. Moretto et al., 2012

Licensee PAGEPress, Italy

Journal of Agricultural Engineering 2012; XLIII:e27

doi:10.4081/jae.2012.e27

This article is distributed under the terms of the Creative Commons Attribution Noncommercial License (by-nc 3.0) which permits any noncommercial use, distribution, and reproduction in any medium, provided the original author(s) and source are credited.

\section{Introduction}

In the last 200 years, most Italian and European rivers have suffered considerable pressure from human intervention both at basin and channel levels (Ward et al., 1999; Liébault and Piégay, 2002; Gurnell and Petts, 2002; Gurnell et al., 2009; Comiti et al., 2011). Phases of deforestation and reforestation, channelisation, sediment mining, urbanisation, dam building, torrent-control works, water diversion for agriculture and hydro-electric power generation, and many other interventions have modified natural water and sediment fluxes and boundary conditions. In particular, the deficit of available sediment in many Italian rivers was aggravated by mining activities for building purposes within the channel over the period 1960-1980 (Comiti et al., 2011). These events have, in turn, caused different morphological adjustments that are generally greater than those to be expected from natural fluvial evolutionary dynamics.

A common trend of Italian Alpine rivers is the considerable channel responses identified over the last decades, consisting in a major phase of narrowing and incision followed by more recent equilibrium and/or widening phases. The morphology of fluvial systems has changed considerably. If past evidence of a more common diffusion of multi- thread channels is well documented, nowadays also braided reaches, such as stretches of the Piave in the Alpine foothills and the Brenta in northeastern Italy, show braiding indexes that are clearly lower in respect to previous conditions. Recent studies carried out on the Brenta river (Moretto, 2010; Simonetto, 2010; Kaless et al., 2011; Moretto et al., 2011, 2012a, 2012b; Rigon et al., 2012b) highlighted that human intervention has strongly modified the sediment regime, in particular during the second half of $20^{\text {th }}$ century. Understanding fluvial processes and channel evolution are crucial for a sustainable management and restoration of heavily impacted rivers.

The type of islands present in a riverine system can also help to describe the river processes. Gurnell and Petts (2002) came to the conclusion that most European rivers were once island-dominated (pre1900), but that these islands have disappeared due to human interference. In Europe, except for agricultural and urban developed areas, islands remain a common feature of riverine landscapes, such as the Tagliamento River in north-eastern Italy (Ward et al., 1999; Gurnell et al., 2001). The presence of a certain species of plant on the islands can help to determine the flow conditions in the area. Some plant species have specific growth requirements, such as inundation duration, gradient, and particle size (Picco et al., 2012a, 2012b). Some large rivers are flow-regulated to some degree and this can have several implications for fluvial island development and stability. Dams reduce flood peaks, increase base flow, and store sediments (Kondolf, 1997; Braatne et al., 2003). As a result of the human impact and unwise management, most braided rivers have evolved towards incised singlethread channels (Piégay et al., 2006). In this sense, the sediments 
transported downstream of a dam represent only a fraction of the normal sediment load. Flow regulation can, in fact, reduce bed-load transport by up to $50 \%$ (Hicks et al., 2003) resulting in an armoured bed with sediment supply issues on downstream reaches. In turn, also biological habitats and interactions between biotic and hydrological processes are generally reduced (Poff et al., 2007). While dams can reduce the erosion and removal of fluvial islands, they can also promote bank attachment by decreasing the sediment supply and the downstream transport capacity, leading to the deposition of tributary input sediments.

This paper deals with the morphological evolution and the associated island dynamics of the lower course of the Brenta River over the last 30 years. Previous studies in this river basin have analysed: i) morphological changes of the river channel (Moretto, 2010; Simonetto, 2010; Moretto et al., 2011; Rigon et al., 2012b); ii) land use changes within the fluvial corridor and the abundance of in-channel wood (Mao et al., 2012; Rigon et al., 2008, 2012a); and iii) sediment transport, sediment budget, debris flow modelling and hazard in the headwaters (Rickenmann et al., 1998; Bathurst et al., 2003; Lenzi et al., 2003, Mao et al., 2005; Lenzi, 2006; Segato et al., 2006; Mao and Lenzi, 2007). The evolution of this reach of the Brenta River is quite interesting to analyse since it has been put under pressure by human activity through an intense hydropower scheme and past gravel mining activities.

In comparison to previous papers dealing with similarly regulated Italian rivers, this present study looks at three main points. First, we present a combined analysis of channel adjustments considering island dynamics during the last 30 years. We then look at the varying channel response shown on a sub-reach level and we connect this to both natural- and human-induced factors at the same level. The third innovation is represented by the detection and quantification of the short-term morphological adjustments at a sub-reach level through comparison of two subsequent Light Detection and Ranging (LiDAR) data surveys. In particular, evidence of channel changes and erosion and deposition patterns are analysed for two years: 2010 and 2011. This period was characterised by the presence of two consecutive flood events with recurrence interval (RI) of eight and ten years, respectively.

The specific objectives of this paper are: i) to quantify the morphological changes, both in bed planform and bed elevation; ii) to analyse the island dynamics; iii) to identify the driving factors affecting channel evolution and island dynamics thus predicting the most likely future trends.

In detail, the following research hypotheses will be considered: i) planform (narrowing/widening) and vertical (incision/aggradation) processes are correlated; ii) gravel mining is the main factor driving recent channel and island dynamic changes; iii) recent channel changes at a sub-reach level may be considered short-term fluctuations related to specific flood events, rather than real medium-term adjustments.

\section{General settings of the study area}

\section{Climatic, geological and morphological settings of the Brenta basin}

The Brenta is one of the most important rivers of the Italian Alps flowing into the upper Adriatic Sea (Figure 1). The drainage basin covers a surface of $1787 \mathrm{~km}^{2}$ (Brenta basin closed at Limena gauging station). The river is $174 \mathrm{~km}$ long and can be divided into two main reaches: an upper $70 \mathrm{~km}$ stretch flowing within the mountain basin, and a $104 \mathrm{~km}$ stretch flowing within the Venetian floodplain area. The upper basin features a typical continental-alpine climate with an annual rainfall of approximately $1500 \mathrm{~mm}$ (Giuliacci et al., 2001). The geological setting is rather complex and includes limestone, dolomite, gneiss, phyllite, granite and volcanic rocks. Regarding its morphology, the river flows out from the Caldonazzo lake featuring a straight channel, and then evolves in a braided-wandering pattern in the foothills area (Moretto, 2010; Simonetto, 2010; Moretto et al., 2011) before becoming meandering and then heavily rectified in its lower course.

\section{Human impact on the Brenta basin}

During the past centuries, the Brenta River has been affected by multi-spatial and temporal human intervention that has heavily modified its natural features. The magnitude and consequences of such disturbances have increased during the last 100 years. The human impact mostly consists in direct interventions, such as channelisation, gravel mining and damming, levee and groin construction. In particular, gravel mining has been recognised as the human intervention with the greatest impact on channel morphology. This has interested mostly the lower reaches, especially between 1950 and 1980 when a large volume of sediments was removed, exceeding replenishment rates and producing a significant alteration in sediment fluxes. Indeed, official estimates set volumes of mined sediment at approximately 6-8 million $\mathrm{m}^{3}$ from 1953 to 1977. The second most important human disturbance has been the construction of several dams which have reduced both flow and sediment discharges. The largest dam, built in 1954 for hydroelectric power generation and irrigation purposes, is the Corlo dam in the Cismon torrent with its 42 million $\mathrm{m}^{3}$ reservoir. It is also worth mentioning the impact of torrent-control works in the low-order mountain streams and the recent trend for natural basin reforestation. This has

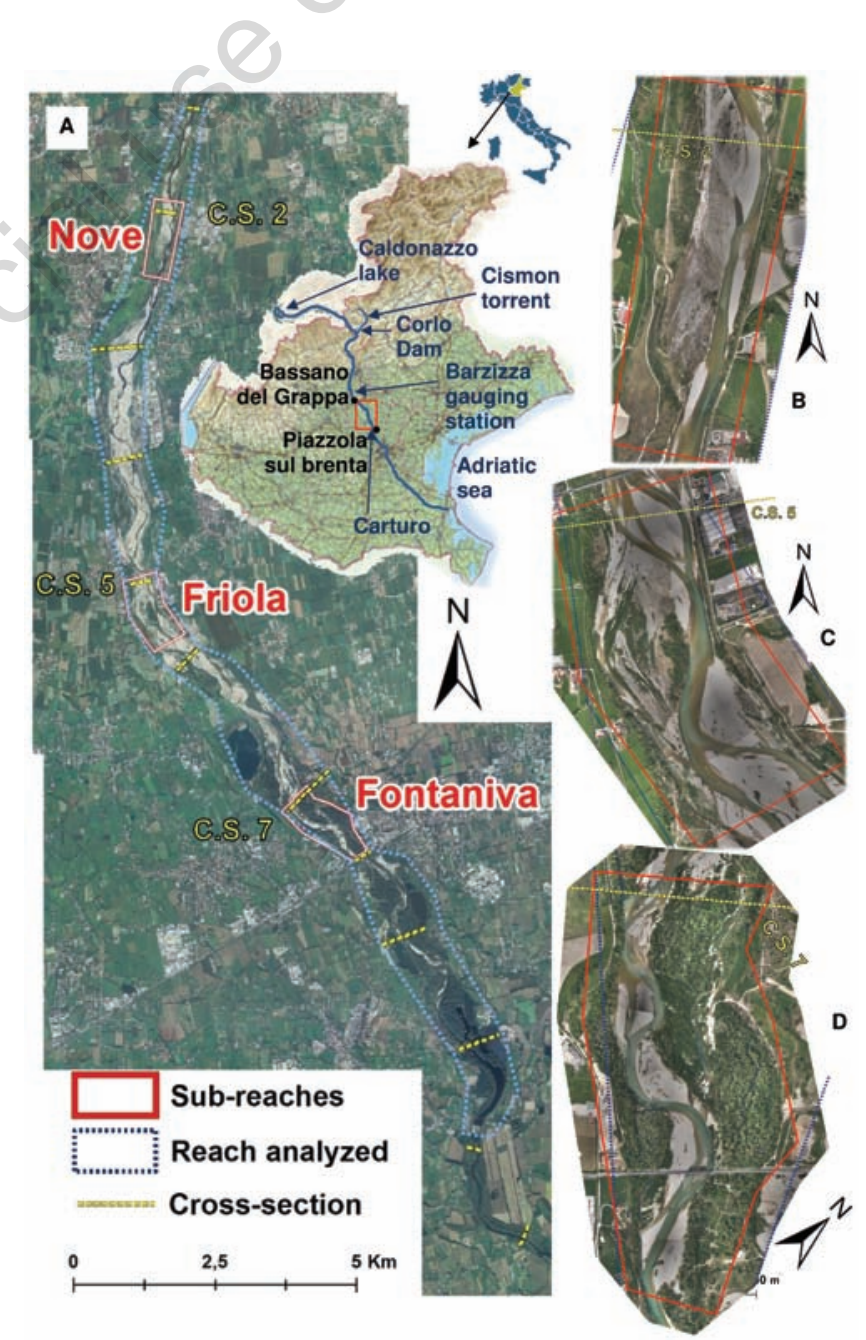

Figure 1. General view of the Brenta reach (A) and sub-reaches: Nove (B), Friola (C), and Fontaniva (D). 
reduced the sediment yield at the basin level contributing to channel incision. The result of all this has been the narrowing of the average river bed width from around $440 \mathrm{~m}$ at the beginning of the $1800 \mathrm{~s}$ to around $220 \mathrm{~m}$ in 2003, and the remarkable channel incision up of to 7 m (Moretto, 2010; Moretto et al., 2011; Rigon et al., 2012b).

\section{Study reach and sub-reaches}

The reach of the Brenta river considered in the present study is approximately $20 \mathrm{~km}$ long and is located in the foothill area of the basin (basin area closed at Barzizza gauging station, $A=1567 \mathrm{~km}^{2}$ ) between the towns of Bassano del Grappa and Piazzola sul Brenta (Figure 1A). The upper part of the reach, located immediately downstream of the mountain area, features a fairly straight channel and a narrow alluvial plain. In its middle portion, the river widens, the slope is reduced (approx. 0.3\%) and the river features a braided pattern with islands. In its lower part, the river shows a wandering pattern with higher sinuosity $(\approx 1.12)$ and the presence of extensive riparian vegetation on the floodplains. Within the study reach there is a wide range of human infrastructures, such as embankments, bridges, and transversal works such as the Carturo transverse (located at the very end of the study reach). Also, the floodplains are characterised by the presence of urbanised areas, and much of the discharge is diverted for irrigation and hydroelectric purposes (Rigon et al., 2012b).

Three sub-reaches $1.5 \mathrm{~km}$ long and $5 \mathrm{~km}$ apart have been identified within the study reach in order to assess in detail the evolution of the active channel width and the extent of vegetation over the last 30 years. The sub-reaches are named after the nearby villages of Nove (Figure 1B), Friola (Figure 1C), and Fontaniva (Figure 1D). The most important characteristics of the sub-reaches are reported in Table 1. The Nove sub-reach features a single straight channel and the average width of the active channel (i.e. including bars) is around $390 \mathrm{~m}$. Its dynamics is influenced by both a bridge and a bed-still lying just upstream, and by a longitudinal embankment on its left side. The Friola sub-reach is wider (484 m), has a braided pattern with densely positioned islands, and the floodplains are sparsely vegetated. Its dynamics is influenced by a bridge upstream, embankments on its left side, and an active gravel mining activity on its right side. In the lower sub-reach (Fontaniva), the Brenta River features an island-braided pattern, and the active width increases to up to $678 \mathrm{~m}$. Again, the sub-reach is influenced by longitudinal embankments and bridges.

\section{Materials and methods}

\section{Cross-sections and longitudinal profile}

Twelve historical cross-sections, described in detail in Moretto (2010), lie within the study reach (Figure 1A). They were first surveyed in 1932, and then in 1997 with a total-station device. In 2010, the first 10 cross-sections were re-surveyed with a differential global positioning system (DGPS) with a maximum vertical error of $\pm 0.02 \mathrm{~m}$. Crosssections 2, 5 and 7 are located in the Nove, Friola, and Fontana subreaches, respectively (Figure 1). Since LiDAR surveys taken in 2010 and 2011 are available for the entire sub-reaches (see below for details), the cross-sections 2,5 and 7 for 2011 were derived from filtered LiDAR points and channel bed points obtained by an image analysis of coloured aerial photographs taken at the same time (Moretto et $a l ., 2012 \mathrm{a}, 2012 \mathrm{~b})$. The vertical error of these cross-sections was estimated to be around $\pm 0.15 \mathrm{~m}$. The longitudinal profile along the river reach was derived from an averaged cross-section elevation, calculated using all points within the active channel (i.e. excluding banks and floodplains).

\section{Flow regime}

Flow regime was measured at the basin outlet, Barzizza Gauging Station, by the ex-Italian National Hydrographical and Hydrological Agency from 1924 to 1996, and by the Regional Agency for Environmental Prevention and Protection of Veneto (ARPAV) from 1997 to 2010. The station is located $5 \mathrm{~km}$ upstream of the analysed reach (Figure 1). Mean daily discharges (Qd) were available for two periods: 1924-1996 and 2005-2011. From 1997 to 2004, Qd were obtained through the application of the stagedischarge rating curve given and validated by ARPAV for the period 20052011. All values of the two series of data were checked and missing data were calculated by cross-correlation and interpolation techniques (Kaless et al., 2011). Nevertheless, values of water levels recorded at the Barzizza station were not available for the most part of the years 1942, 1943, 1944, 1945, 1967, 1968 and 1984 and thus the resultant mean daily water discharge could not be calculated by interpolation techniques (Figure 2). A comparison between maximum instantaneous peak water discharge, maximum hourly daily water discharge, and maximum main daily discharge, was carried out for 24 flood events measured in the field by the ARPAV occurring in the period 2004-2009. Flood events were chosen with the criteria of guaranteeing both the non-dependency between two consecutive floods and to cover a large range of water discharge peak values. A very good correlation was obtained (Kaless et al., 2011) between the values of maximum hourly daily and maximum main daily water discharge $\left(r^{2}=0.96\right)$. Extending this analysis to the entire available data set, a total of seventy nine (79) flood events (Figure 2) were chosen, checked and considered for testing different probability distribution functions and for the flood frequency-return time estimations (see flow regime analysis below).

Table 1. Characteristics of the analysed sub-reaches.

\begin{tabular}{lccccccc} 
& $\begin{array}{c}\text { A } \\
\left(\mathrm{km}^{2}\right)\end{array}$ & $\begin{array}{c}\text { Wbk } \\
(\mathrm{m})\end{array}$ & $\begin{array}{c}\text { Wf } \\
(\mathrm{m})\end{array}$ & $\begin{array}{c}\text { Elv } \\
(\mathrm{m} \text { asl })\end{array}$ & $\begin{array}{c}\mathrm{S}_{(\%)} \\
(\mathrm{mm})\end{array}$ & $\begin{array}{c}\mathrm{D}_{50} \\
(\mathrm{~mm})\end{array}$ \\
Nove & 1.22 & 182 & 390 & 81 & 0.39 & 37 & 87 \\
Friola & 0.62 & 272 & 484 & 53 & 0.26 & 35 & 79 \\
\hline Fontaniva & 0.56 & 316 & 678 & 37 & 0.31 & 31 & 64 \\
\hline
\end{tabular}

A, surface area; Wbk, mean bank full width; $W f$, mean floodplain width; Elv, mean elevation; S, mean channel slope; $D_{x x}$ grain size of the $x^{t h}$ percentile of surface sediments.

Table 2. Technical specifications of aerial image series used in the study.

\begin{tabular}{lcccccc} 
Year & $\begin{array}{c}\text { Px } \\
(\mathrm{m})\end{array}$ & $\begin{array}{c}\text { Approx. } \\
\text { Scale }\end{array}$ & $\begin{array}{c}\text { Hf } \\
(\mathrm{m})\end{array}$ & $\begin{array}{c}\text { Fcl } \\
(\mathrm{mm})\end{array}$ & Date flight & Company \\
1981 & 1.00 & $1: 17000$ & 2600 & 153.13 & April 15 & CGR Parma \\
1990 & 1.00 & $1: 20000$ & 3000 & 152.82 & April 15 & CGR Parma \\
\hline $1994^{*}$ & 0.35 & $1: 20000$ & 8000 & 305.38 & 20 Sept. & CGR Parma \\
1999 & 1.00 & $1: 16000$ & 2500 & 153.26 & July 23 & CGR Parma \\
\hline 2003 & 0.50 & $1: 10000$ & 5400 & 150.00 & May - Nov. & CGR Parma \\
2006 & 0.50 & $1: 10000$ & 5400 & 150.00 & May - Nov. & CGR Parma \\
\hline 2008 A & 0.40 & $1: 8000$ & 1250 & 153.64 & July 15 & Rossi - Firenze \\
2008 B & 0.75 & $1: 16000$ & 2400 & 153.64 & July & CGR Parma \\
\hline 2010 & 0.15 & $1: 12000$ & 2000 & 100.47 & August & CGR Parma \\
2011 & 0.15 & $1: 12000$ & 2000 & $50-35$ & April 12 & OGS \\
\hline
\end{tabular}

$P x$, pixel size; $H F$, height of flight; $F C l$, focal."*1994 flight does not include the Nove sub-reach. 


\section{Identification of geomorphological and island features from aerial photographs}

Islands and riverbed morphological evolution over the last 30 years were analysed using nine series of aerial photographs, always acquired during low-water level conditions (Table 2). Aerial photographs were rectified and co-registered to a common database at 1:5000 using geographical information systems (GIS) software (ESRI ${ }^{\circledR}$ ArcGIS 10, Environmental Systems Research Institute, Redlands, CA, USA). Approximately 40 ground control points were used to rectify each single frame, and third-order polynomial transformations were then applied, obtaining root mean square errors (RMSE) ranging from 0.3 to $1 \mathrm{~m}$. The higher RMSE are for 1981, 1990 and 1999 (1 m of pixel size). These photographs were analysed using the same method described in Comiti et al. (2011) in order to identify the extent of active channel and islands along the whole $20 \mathrm{~km}$ study reach. The active channel is defined as the area without shrub vegetation, thus including unvegetated bars and active and inactive channels, while the fluvial islands include pioneer, young and stable islands according to Gurnell and Petts (2002) classification. In order to analyse the morphological changes along the study reach, active channel and island widths were taken in 85 positions, 250 $\mathrm{m}$ apart in transects perpendicular to the river axis created in a GIS environment.

\section{Photo-interpretation errors}

The errors related to photo-interpretation assessment were performed using the Mount et al. (2003) method. This procedure consists in estimating two independent errors; the first represents the operator error associated with the bank line digitalisation, while the second defines the uncertainty deriving from the air images. Considering the first type, we multiplied the pixel resolution (R) by the mean of the maximum number of pixels (p) of repeat right and left delineations of the bank line. Given that the error range was below $2 \mathrm{~m}$ (among all photo-sets), we decided to group together the offset data for each set, reaching one average pixel error value (p). The distortion degree within each air image was assessed by comparing positions (i.e. corners of buildings) easily identifiable on all photo-sets with those found on the 2006 ortho-photographs. Finally, the difference in distance was measured. Thus, the photographic distortion error considering each image set $(\theta)$ expresses (or represents) the mean difference in distance between points. To complete error identification, the total error in width $\left(\mathrm{E}_{\mathrm{w}}\right.$ ) was assessed by Mount et al. (2003) equation:

$$
\mathrm{E}_{\mathrm{w}}=2^{1 / 2} \mathrm{pR}+2 \theta
$$

Accounting for the polygonal areal error (erosion, channel, islands), we needed to consider two assumptions: i) the constancy (no error) of eroded bank segments, channel length or islands; and ii) the rectangu- lar form of the polygons describing these areas. In this sense, the error assessment related to the area was equal to the product between the polygon length and the width error (Mount et al. 2003).

\section{Light Detection and Ranging data survey}

The sub-reaches were surveyed with LiDAR technology during two subsequent years at low-level stage: August $23^{\text {rd }} 2010$ by BLOM GCR SpA (Parma, Italy) which used an OPTECH ALTM Gemini sensor (Optech Incorporated, Vaughan, ON, Canada), and on April 24 2011 by OGS which used a RIEGL LMS-Q560 sensor. The raw LiDAR data were filtered with the TerraScan software (Terrasolid Ltd., Helsinki, Finland) to obtain ground points (Table 3). The DTM models, with 0.5 ' $0.5 \mathrm{~m}$ of pixel size, were validated with DGPS cross-section surveys. We have estimated the average error propagated into Dem differencing models (DoD) as:

$$
\delta u_{D o D}=\sqrt{\left(\delta z_{\text {new }}\right)^{2}+\left(\delta z_{\text {old }}\right)^{2}}
$$

where $\delta u_{D o D}$ is the propagated error in the DoD, and $\delta z_{\text {new }}$ and $\delta z_{\text {old }}$ are the individual average errors in $\mathrm{DTM}_{2011}$ and DTM 2010 , respectively (Brasington et al., 2003).

Channel bed points, which cannot be derived from LiDAR surveys, were integrated using an image analysis concerning the spectral properties of the colour bands (e.g. Legleiter, 2012). Mean radiometric values were extracted for each point where the observed water depth was

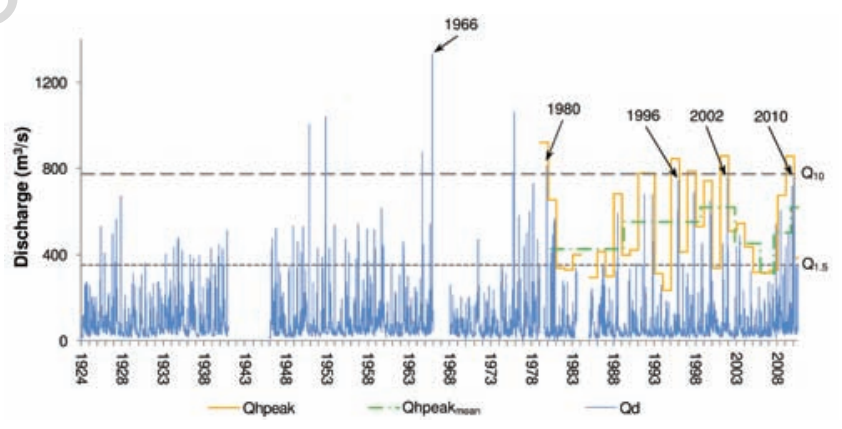

Figure 2. Water discharges (1924-2011) at the Barzizza gauging station. Qd, mean daily discharge; Qhpeak, the maximum hourly discharges registered in the year; $Q h$ peak ${ }_{\text {mean, }}$ average of annual maximum hourly discharge in a comparison of the sequence of aerial photographs from 1981 to 2011 .

\begin{tabular}{|c|c|c|c|c|c|c|}
\hline \multirow[t]{2}{*}{ LiDAR survey } & \multicolumn{2}{|c|}{ Nove } & \multicolumn{2}{|c|}{ Friola } & \multicolumn{2}{|c|}{ Fontaniva } \\
\hline & 2010 & 2011 & 2010 & 2011 & 2010 & 2011 \\
\hline Sub-reach area $\left(\mathrm{m}^{2}\right)$ & 567 & 567 & 837 & 837 & 627 & 627 \\
\hline Average vertical error (m) & 0.20 & 0.20 & 0.20 & 0.20 & 0.20 & 0.20 \\
\hline Average point density (points $\mathrm{m}^{-2}$ ) & 2.1 & 3.1 & 1.8 & 2.6 & 2.3 & 2.0 \\
\hline DGPS points for DTM test & 264 & 540 & 377 & 976 & 257 & 347 \\
\hline TOTAL average DTM uncertainty (m) & 0.16 & 0.16 & 0.24 & 0.16 & 0.26 & 0.17 \\
\hline SuDoD (m) & \multicolumn{2}{|c|}{0.23} & \multicolumn{2}{|c|}{0.29} & \multicolumn{2}{|c|}{0.31} \\
\hline
\end{tabular}

Table 3. Estimated uncertainty for Digital Terrain Models and DEM differencing models.

LiDAR, Light Detection and Ranging data; DGPS, differential global positioning system; DTM, digital terrain model, $\delta u_{D o D}$ propagated error in raster difference between 2011 and 2010. 
measured with a DGPS field survey. Then, a statistical regression analysis was made producing imagery-derived predictions of water depth. According to their spectral properties, red, green and blue bands were used (Moretto et al., 2012a; 2012b). The two subsequent LiDAR surveys were analysed in order to evaluate the geomorphic effects of the previously described flood events; nevertheless in the present paper we only report some preliminary results derived from the analysis of the short-term evolution at a sub-reach level.

\section{Results}

\section{Flow regime analysis}

In order to evaluate their frequency of occurrence, the return interval of each flood was estimated from the maximum annual values of the mean daily water discharge (Qdpeak) over 79 considered hydrological years. Various functions of the hydrological probability distribution (Log Normal, Log Pearson Type III, Frechet, and Gumbel) were tested and the Gumbel distribution (OLS) was chosen, due to the best performance of the Kolmogoroff test. Taking into account the Gumbel distribution and the confidence limits (confidence level 90\%), it was possible to establish the flood values associated with the probability. The bankfull discharge (RI 1.5 years) was calculated to be approximately $350 \mathrm{~m}^{3} \mathrm{~s}^{-1}\left(\mathrm{Q}_{1.5}\right)$, exceeding 2.4 days per year, and the discharge with recurrence interval of ten years was estimated at approximately $750 \mathrm{~m}^{3}$ $\mathrm{s}^{-1}\left(\mathrm{Q}_{10}\right)$. The largest flood event was registered on November $4^{\text {th }} 1966$ with $1330 \mathrm{~m}^{3} \mathrm{~s}^{-1}$ of mean daily discharge (RI 200 years). Figure 2 reports water discharges (1924-2011) at the Barzizza gauging station. The mean daily discharge from 1924 until June 2011 (Qd), the maximum hourly discharges from 1981 to 2011 (Qhpeak), and the average of annual maximum hourly discharge in the comparison of the aerial photographic sequences $\left(\right.$ Qhpeak $\left._{\text {mean }}\right)$ from 1981 to 2011 were then reported. The analysis of data shows that the flow regime of the River Brenta is characterised by rainfall and snowmelt contributions in spring and in autumn. The monthly distribution of discharges shows two very similar maxima: the first concentrated in May and the second concentrated in October and November (Kaless et al., 2011). Also, flood events tend to occur in May, October and November. More than $50 \%$ of all the flood events recorded in the full time series from 1924 to 2011 are concentrated in these three months (Kaless et al., 2011). However, the month with the highest likelihood of occurrence of flood events is always November. Over the last thirty years, four flood events with recurrence interval equal or greater than ten years were registered $(1980,1996,2002$ and 2010). Other active hydrological years were 1981, 1989, 1992, 1993, 1998, 2000 and 2009 with Qdpeak of 569, 594, 682, $682,691,650$ and $605 \mathrm{~m}^{3} \mathrm{~s}^{-1}$, respectively. Two severe flood events affected the Brenta River in November and December 2010. The first flood, caused by prolonged and extended rainfall reaching $300 \mathrm{~mm}$ with local maximums over $500 \mathrm{~mm}$, lasted from the $31^{\text {st }}$ of October to the $2^{\text {nd }}$ of November 2010, featuring an Qd of $720 \mathrm{~m}^{3} \mathrm{~s}^{-1}$. The second flood, the result of intensive precipitation, occurred between the $21^{\text {st }}$ and the $26^{\text {th }}$ of December 2010 mainly in the pre-alpine and foothills areas, and featured an Qd of $759 \mathrm{~m}^{3} \mathrm{~s}^{-1}$ (Qdpeak of 2010). Rainfall exceeded $150 \mathrm{~mm}$ with local maximums of $300-400 \mathrm{~mm}$ and at Barzizza gauging station the river registered higher hydrometric levels than the first flood event.

\section{Bed-level changes along the study reach}

The vertical adjustment of the riverbed was analysed using 10 historical cross-sections measured from 1932 to 2010. Compared with the profile of 1932 (Figure 3), it appears that the river experienced an incision of up to 5-7 m except for section 1 , where the vertical adjustments were lower than $-0.35 \mathrm{~m}$. In contrast, over the last 13 years (1997-2010), the riverbed experienced a general incision of around $0.2 \mathrm{~m}$. However, significant differences in vertical adjustments appear along the reach. In fact, in the upstream portion of the study reach, from section 1 to 5 (including Nove and Friola sub-reaches) the average vertical adjustment of the active-channel during the last 13 years ranges from -0.35 $\mathrm{m}$ (section 1) to $-0.92 \mathrm{~m}$ (section 2 ), with an average value of $-0.7 \mathrm{~m}$ (average level of the active channel). If the talweg line is considered, the incision of the river is equal to $1.78 \mathrm{~m}$ in correspondence to section 1. The middle portion of the study reach seems to be in an equilibrium condition since a vertical variation of only $-0.01 \mathrm{~m}$ and $0.11 \mathrm{~m}$ has occurred in section 6 and 7, respectively. Inversely, the lower portion of the study reach has been aggrading from 1997 to 2010, since the mean level of the last three historical sections ( 8,9 and 10) has risen between $0.42 \mathrm{~m}$ and $0.48 \mathrm{~m}$. In section 7 , we can appreciate the aggradation of the river along the talweg accounting for $0.69 \mathrm{~m}$ in the period 1997-2010 (Rigon et al., 2012b). The channel slope in the whole study reach remained virtually unchanged from 1997 to 2010 , passing from $0.0036 \mathrm{~m} \mathrm{~m}^{-1}$ to $0.00356 \mathrm{~m} \mathrm{~m}^{-1}$ with a relative variation of only $1 \%$. Analysing in detail the inter-reach sections, two opposite tendencies can be recognised: on the one hand, a relative slope increase of approximately $6 \%$ (from 0.00495 to $0.00526 \mathrm{~m} \mathrm{~m}^{-1}$ ) between sections 1 and 2
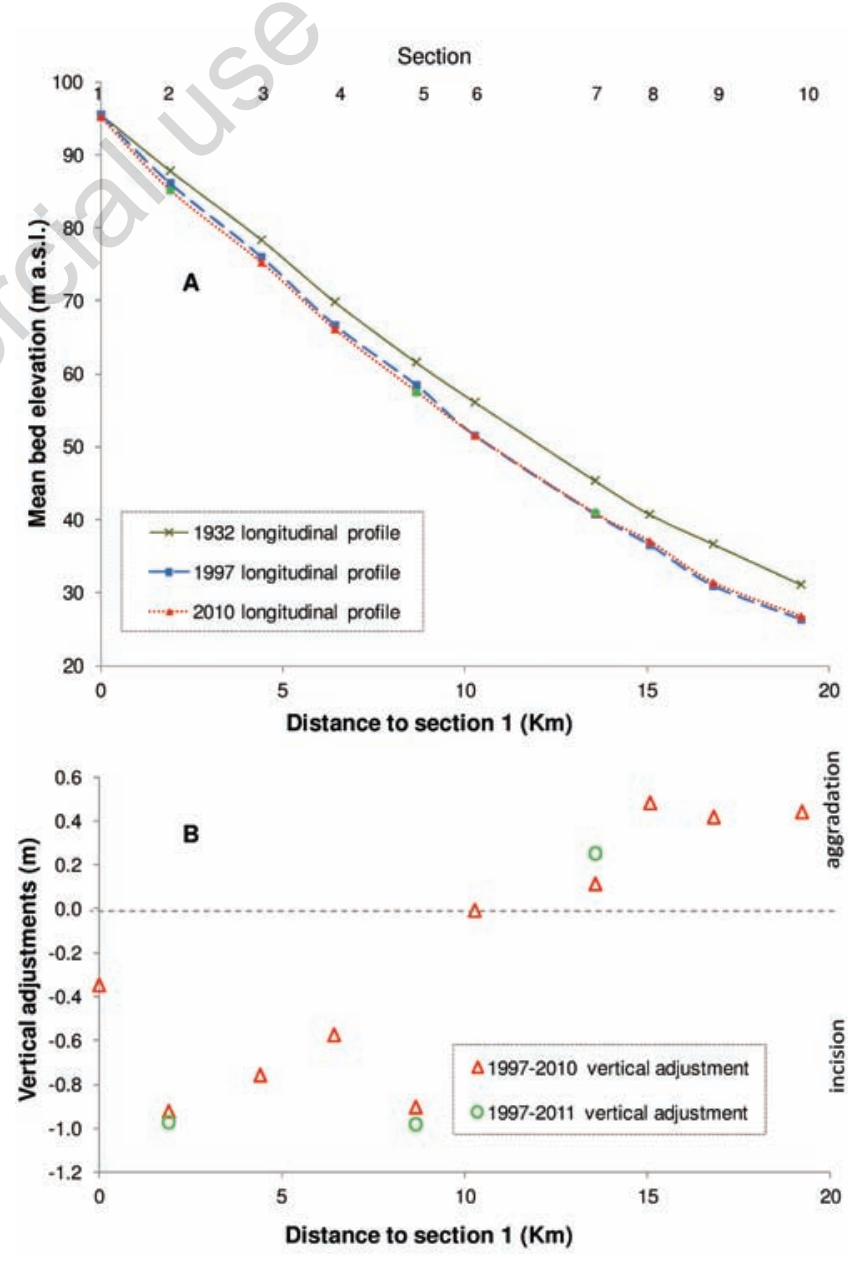

Figure 3. Longitudinal profiles of the Brenta River from 1932 and 1997, 2010, and 2011 surveys. (A) 2011 sections are derived from the Light Detection and Ranging data survey and are available only for the study sub-reaches (sections 2, 5 and 7); (B) variation in average bed elevation as derived from the comparison of crosssections along the study reach. 
at Nove, whereas on the other hand, a relative slope reduction of approximately $13 \%$ (from 0.00429 to $0.00374 \mathrm{~m} \mathrm{~m}^{-1}$ ) between section 5 and 6 at Friola, was observed, respectively (Moretto et al., 2011). The analysis of the cross-sections derived from the 2011 LiDAR survey confirmed the vertical adjustment trends from 1997 to 2010. The mean elevation of sections 2 and 5 experienced a further reduction $(5$ and $8 \mathrm{~cm}$, respectively), and section 7 increased its elevation of $14 \mathrm{~cm}$ if compared to 2010. However, it should be noted that the 2011 cross-sections could be affected by a greater error than 2010 since they are derived from a LiDAR survey (see below). Sections 2, 5 and 7 (lying in the Nove, Friola and Fontaniva sub-reaches, respectively) are shown in Figure 4, and the horizontal line represents the bank-full level as surveyed in the field in 2010. Incision and narrowing tendencies are evident in the three cross-sections. In section 5 (Figure 4B), the main channel shifted progressively leftwards and reached the main embankment. A different behaviour pattern was observed in the lower portion of the reach shown by the fact that section 7 (Fontaniva, Figure 4C) has remained practically unchanged over the last 13 years.

\section{Changes in the active channel area and width along the whole study reach}

The analysis of the extent of the active channel by aerial photographs at the entire reach level has confirmed remarkable fluctuations during the last 30 years (Rigon et al., 2012b). Figure 5 shows the temporal evolution of the surface area of the active channel, fluvial islands and floodplain area over the last 30 years. Five significant periods characterised by different dynamics of active channel changes could be identified: 1981-1990, 19902003, 2003-2008, 2008-2010 and 2010-2011. The first and third periods are characterised by a decrease in the active channel surface (-148 ha and -70 ha, respectively), whereas the second, the fourth, and the fifth periods are characterised by an increase in the active channel surface (135 ha, 10 ha and 41 ha, respectively). Figure 6 shows the longitudinal variation of the
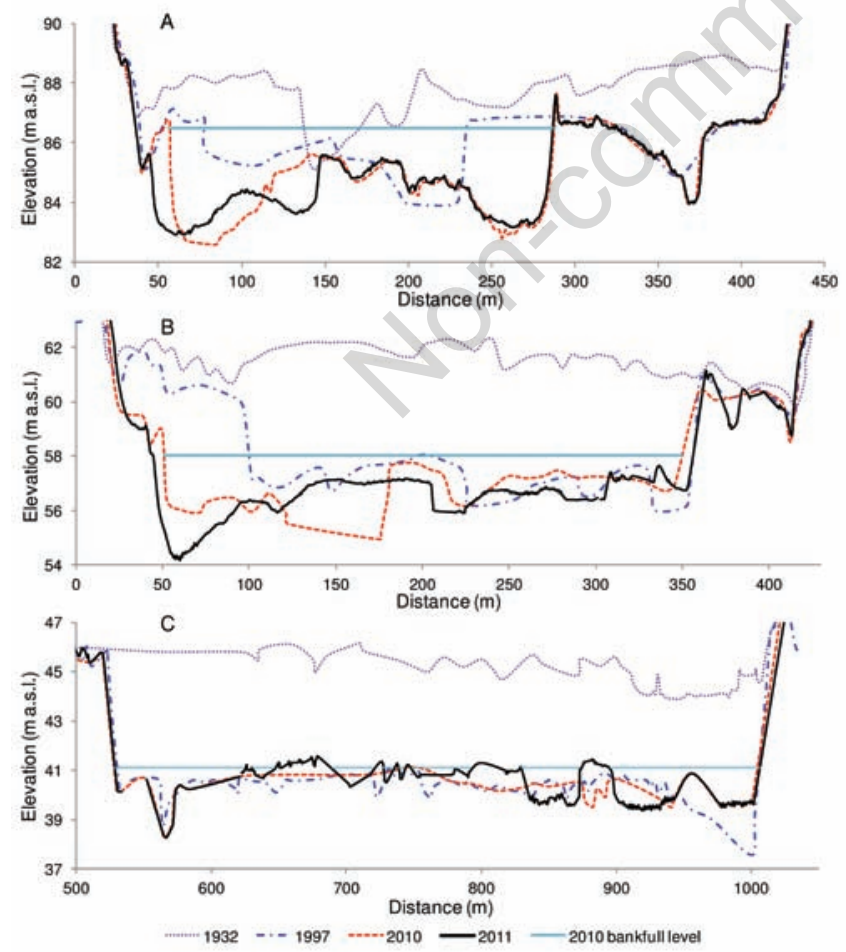

Figure 4. Evolution of historical cross sections 2, 5 and 7 for the years 1932, 1997, 2010 and 2011 located, respectively, in Nove (A), Friola (B) and Fontaniva (C).
Table 4. Temporal variation in the average active channel width in the entire reach and sub-reaches. Data derived from the intersection of 85 transects (in geographical information systems) with interpretation of aerial photographs.

\begin{tabular}{llllllllll}
$\begin{array}{l}\text { Average } \\
\text { width }(\mathrm{m})\end{array}$ & 1981 & 1990 & 1999 & 2003 & 2006 & 2008 & 2010 & 2011 \\
Whole reach & 266 & 181 & 197 & 226 & 225 & 200 & 196 & 215 \\
Nove & 208 & 127 & 226 & 205 & 188 & 171 & 192 & 203 \\
\hline Friola & 306 & 180 & 282 & 361 & 337 & 333 & 328 & 352 \\
Fontaniva & 333 & 187 & 188 & 194 & 139 & 137 & 164 & 196 \\
\hline
\end{tabular}

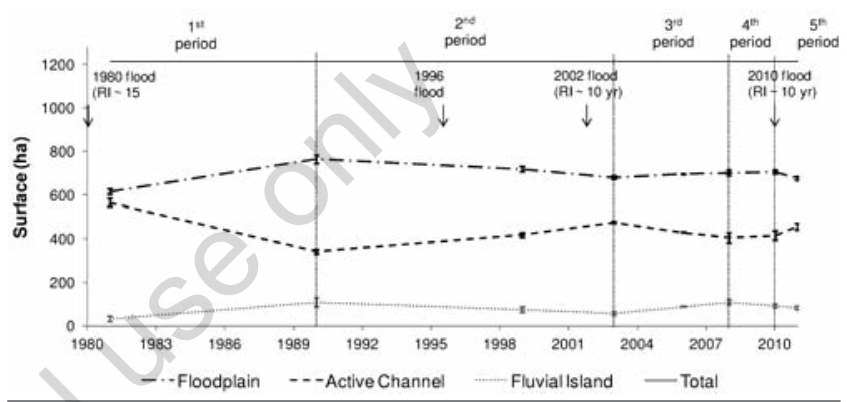

Figure 5. Temporal variation with error bars of the surface of the active channel, floodplain and islands in the reach of the Brenta River analysed.

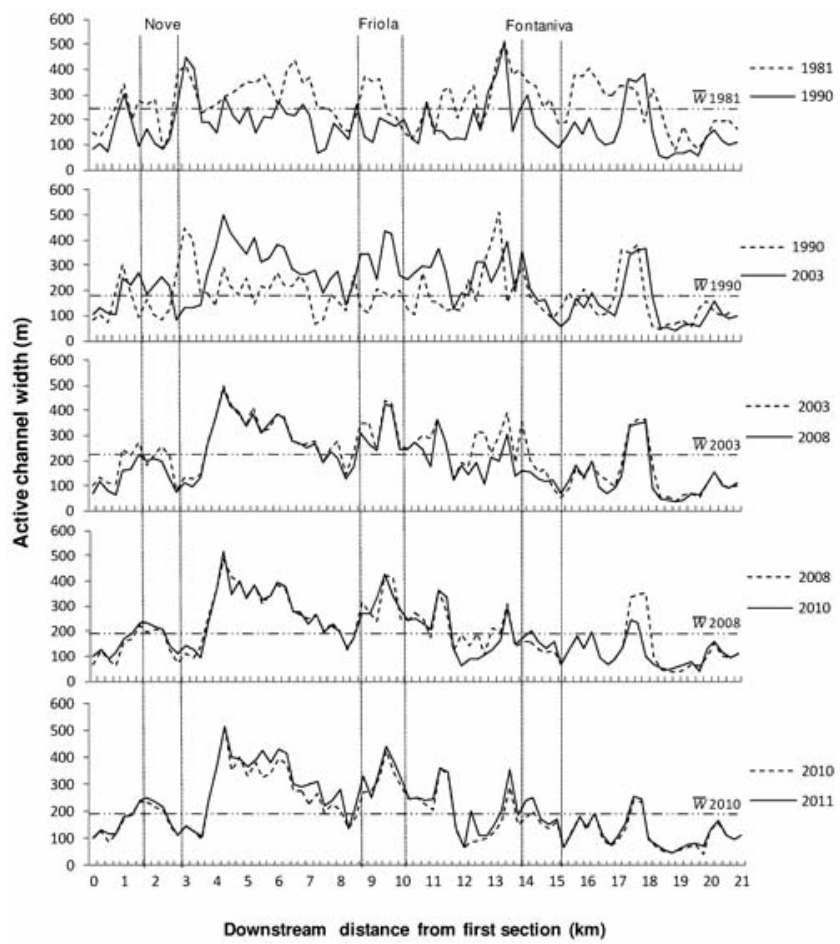

Figure 6. Active channel evolution over the last 30 years divided into five significant periods characterised by different morphological trends. 
active channel width within the 5 identified periods characterised by different geomorphic behaviours. The average values of channel width for the entire reach and sub-reaches are reported in Table 4. During the first nine years of the analysed period (1981-1990), the average active channel width decreased from $266 \mathrm{~m}$ to $181 \mathrm{~m}\left(9.44 \mathrm{~m}_{\text {year-1 }}^{-1}\right)$. The active channel narrowing seems to have occurred along the whole river reach, except for a rather marked enlargement that occurred near the Fontaniva sub-reach (Figure 6). In the period 1990-2003, there was an inverse tendency, characterised by an increase in the average width, up to $16 \mathrm{~m}$ (from 1990 to 1999, at the rate of $1.78 \mathrm{~m} \mathrm{year}^{-1}$ ) and then further accounting for $29 \mathrm{~m}$ from 1999 to $2003\left(7.25 \mathrm{~m}\right.$ year-1 $\left.^{-1}\right)$. The average widening trend is not uniformly distributed along the reach, but it appears to be more concentrated between the fourth and thirteenth kilometre. In the most recent years (2003-2008), the active channel width has been reduced again from $226 \mathrm{~m}$ to $200 \mathrm{~m}\left(5.2 \mathrm{~m} \mathrm{year}^{-1}\right)$. This average trend is mainly due to intense localised narrowing processes that have occurred around the thirteenth kilometre, while in the rest of the channel, the width remained fairly constant. During the period 2008-2010, there was a slight narrowing phase concentrated at around the thirteenth and eighteenth $\mathrm{km}$ along the study reach from $200 \mathrm{~m}$ to $196 \mathrm{~m}$ ( $\left.2 \mathrm{~m}_{\mathrm{mear}}{ }^{-1}\right)$, followed by a very recent enlargement phase between 2010 and 2011 from $196 \mathrm{~m}$ to $215 \mathrm{~m}$, respectively, with a rate equal to $19 \mathrm{~m}$ year $^{-1}$ which is the largest variation registered in the last thirty years. Overall, the active channel width decreased by $51 \mathrm{~m}$ from 1981 to 2011, even if different temporal trends are observed during the studied period and along the reach. It is worth noticing the effect of the November and December 2010 floods (RI=8 and 10 years) that caused a well distributed widening of the channel along the whole reach (Figure 6).

\section{Changes in island area and width along the whole study reach}

The extension of islands within the entire reach (Figure 5) was calculated, as for the active channel area, by photo-interpretation from the historical series of aerial photographs from 1981 to 2011. It is interesting to observe that the variation in island area reflects the trend of the active channel area. The first phase from 1981 to 1990 is characterised by an increase of 77 ha of islands and a decrease in the active channel. The second phase from 1990 to 2003, is characterised by 14 over-bankfull floods; of these one was higher than the 10-year return interval in 2002 , and features a marked decrease in islands area ( -52 ha). Afterwards, island area increased due to the lack of high-magnitude floods from 2003 to 2008 (52 ha). The phase from 2008 to 2010 is characterised by a reduction of 17 ha in island area, followed by another decreasing trend accounting for approximately 10 ha from 2010 to 2011. Major island extension values (108 ha in 1990 and in 2008) are associated to major narrowing periods of the active channel (341 ha in 1990 and 405 ha in 2008). Reversely, the minimum island extension coincides with the maximum extent of the active channel area (1981), equal to $51 \%$ of the entire area of the river corridor.

\section{Changes in active channel and island areas at the sub-reach scale}

The trend of the morphological variations of the Brenta River in the medium- and short-term was not consistent along the whole study reach. The different dynamics over time of the active channel and extent of islands can be seen by examining the three selected subreaches, Nove, Friola and Fontaniva, separately. The relative changes in the unvegetated active channel and extent of islands are reported in Figure 7, and were derived from detailed photo-interpretation of fluvial forms carried out at the sub-reach level (Figure 8). Figure 7A shows the surface (ha) variation in the active channel along the three study reaches during the analysed period. In the first period (1981-1990), it is possible to observe a general decrease of approximately $35 \%, 42 \%$ and $40 \%$

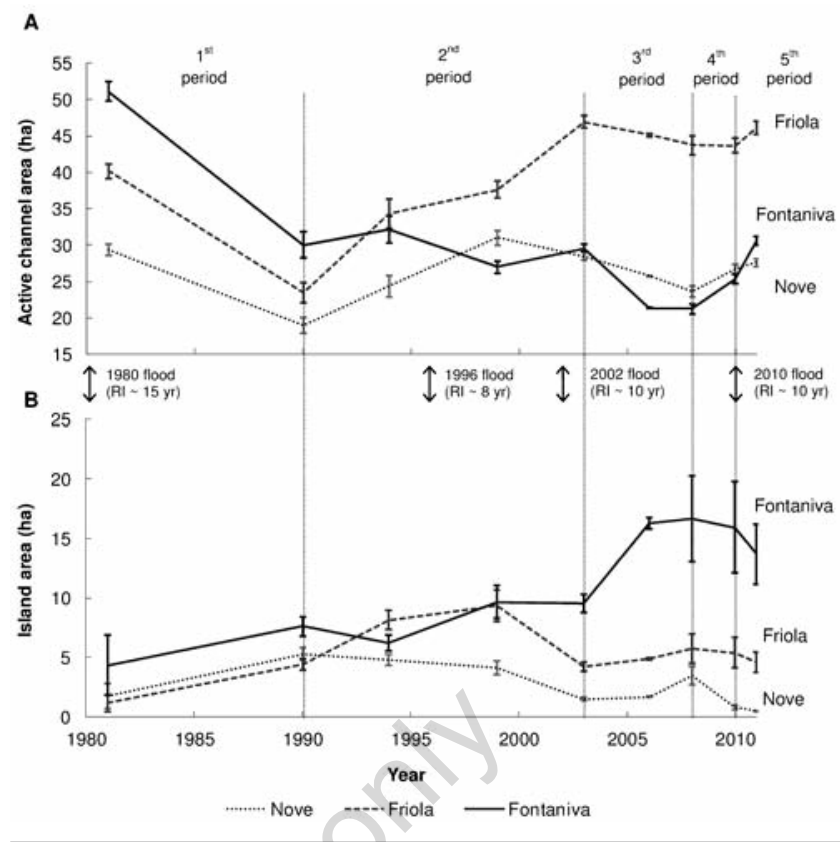

Figure 7. Temporal variation with error bars of active channel (A) and island (B) extent at the sub-reach scale. A photograph was not available for the Nove sub-reach for 1994.

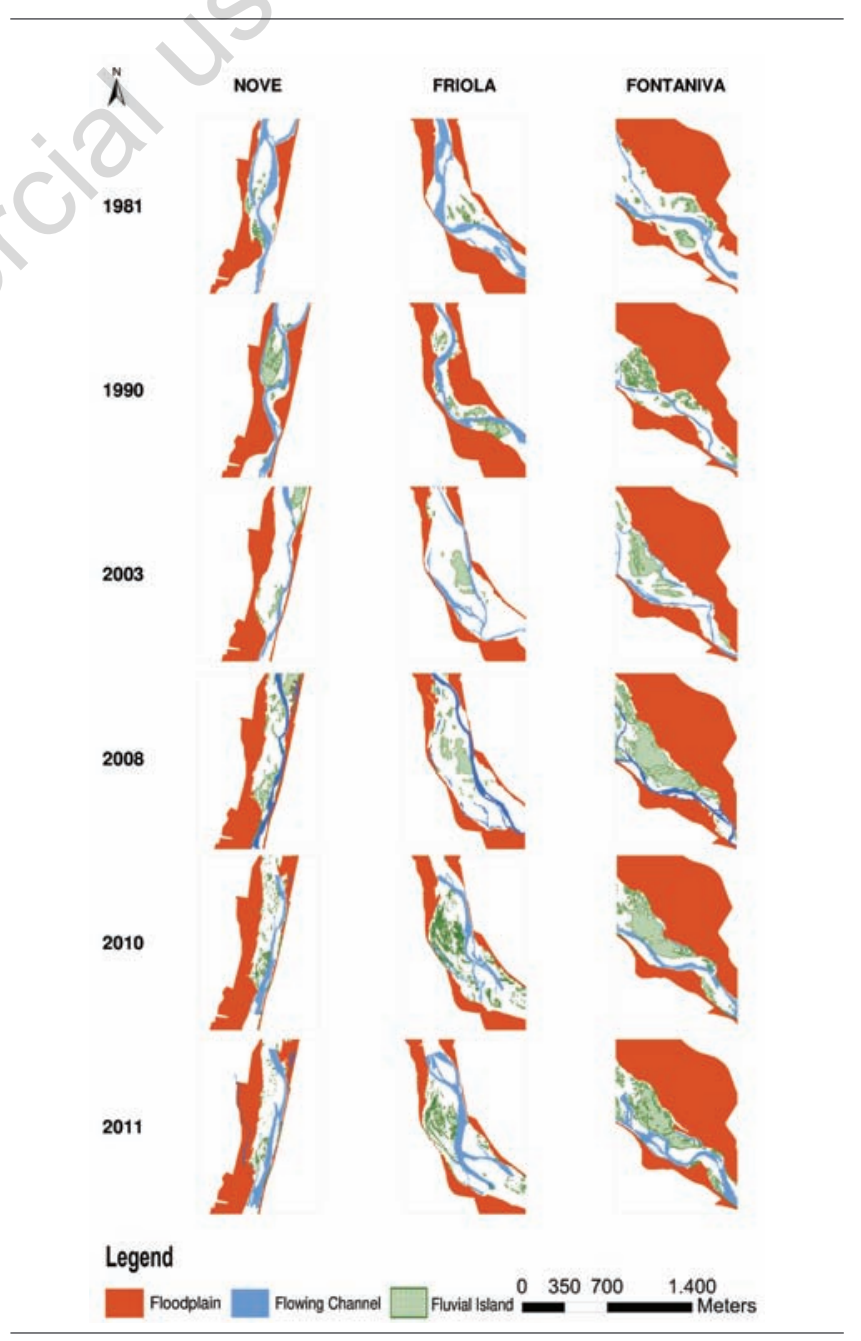

Figure 8. Plan form evolution: Nove, Friola, and Fontaniva subreaches, 1981-2011. 
of the active channel surface in Nove, Friola and Fontaniva sub-reaches, respectively. During the second period (1990-2003), a different behaviour pattern among the sub-reaches can be observed: i) Friola: the active channel area doubles; ii) Fontaniva: there are fluctuations with a slight increase from 1990 to 1994 (7\%), a subsequent strong decrease from 1994 to 1999 (15\%) and a final new consistent increase until 2003 (9\%); iii) Nove experiences an increasing trend from 1990 to 1999 (63\%) followed by a slight areal reduction until 2003 (8\%). The third phase (2003-2008) shows a fairly uniform tendency among the three sub-reaches where a reduction of their active channel area, with a rate ranging from $7 \%$ (Friola) to $28 \%$ (Fontaniva), can be observed. Over the fourth period (2008-2010), Nove and Fontaniva sub-reaches experienced an increase in active channel surface of approximately $13 \%$ and 19\% respectively, while there were no relevant changes in Friola (Figure $7 \mathrm{~A})$. During the fifth period, there was an increase in all the sub-reaches with a maximum value registered in Fontaniva (20\%).

Considering the temporal trend of island evolution, different subreaches experienced a rather different event diverging, in most cases, from the overall tendency. The most downstream reach (Fontaniva) is characterised by a progressive reduction in the active channel area over recent years (Figures 7 and 8) and by a significant increase in the in-channel vegetation of approximately 53\% from 1981 to 1990. Subsequently, it is possible to observe a strong decrease from 1990 to 1994 of approximately 18\% and another great increasing phase of approximately 54\% from 1994 to 1999 . After a very low decrease of approximately 1\% from 1999 to 2003, it is possible to observe a new strong increasing phase from 2003 to 2008 of approximately $74 \%$ and, finally, a new decreasing period from 2008 to 2011 of approximately $18 \%$. Looking at the Friola sub-reach, it is possible to observe a very strong increase in the in-channel vegetation from 1981 to 1999 of approximately 715\%, followed by a consistent decrease from 1999 to 2003 of approximately 54\%. Another period of increases of approximately $35 \%$ can be observed from 2003 to 2008 and a final contraction phase from 2008 to 2011 of approximately $20 \%$. Along the Nove subreach it is possible to observe a strong period of increase of approximately 199\% from 1981 to 1990 and a consequent consistent decrease from 1990 to 2003 of approximately $71 \%$. After that, during a very short period from 2003 to 2008, it is possible to observe another period of significant increases of approximately $131 \%$ and a final contraction of approximately $86 \%$ from 2008 to 2011 .

\section{Discussion}

\section{Morphological adjustments along the Brenta River}

The relationship between vertical adjustment of the average crosssectional elevation and the associated changes in active channel width was evaluated using ten historical cross-sections and considering two different periods: 1932-1997 and 1997-2010. Aerial photographs taken in 1999 and 2010 were also used to improve the interpretation of the width changes of the active channel along the selected cross-sections. In Figure 9, lateral and vertical adjustments in the extent of active channel along the 10 cross-sections are shown. In the period 1932 1997 , no significant correlation was seen between the incision/narrowing phase (except for section 1), vertical and lateral adjustments $(R$ Spearman; $\mathrm{P}>0.05$ ). The weak correlation between vertical and planimetric responses in the case of the Brenta River could be related to the different temporal and spatial extent of sediment dynamics. Similar processes have occurred in the Piave river where channel widening and incision occurred at the same time from 1991 to 2006 (Comiti $e t$ al., 2011). The weak relationship between vertical and planimetric adjustments in the Brenta River may be due to the fact that the subreaches behave differently. In fact, in some sections (e.g. section 6), the incision phase finished between 1970 and 1980, whereas in other sections (e.g. section 2) the narrowing tendency continued also after 1997. Changes in the active channel width were very different in the period 1997-2010, considering that the narrowing phase was finished (Figure 9 ) and the widening trend was continuing only in some sections (sec-

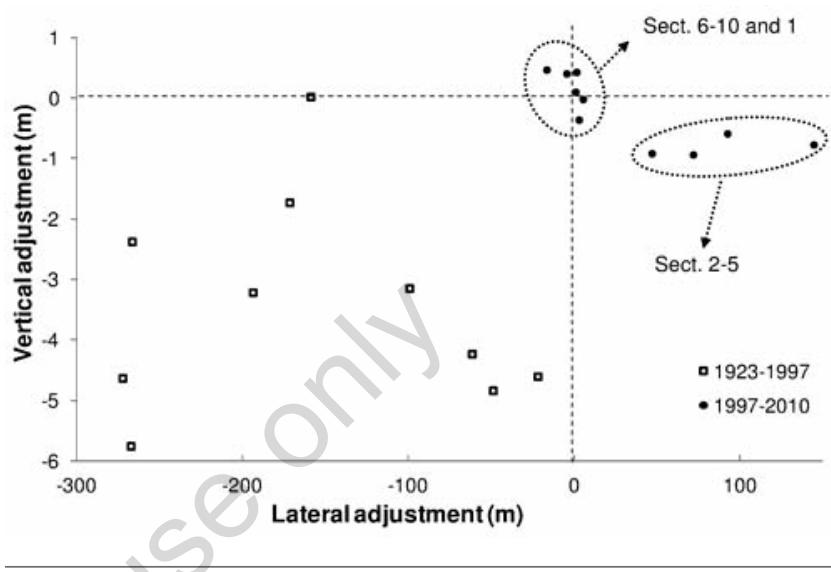

Figure 9. Relationship between the changes in elevation of the bankfull stage and changes in active channel width evaluated in 10 historical cross-sections.

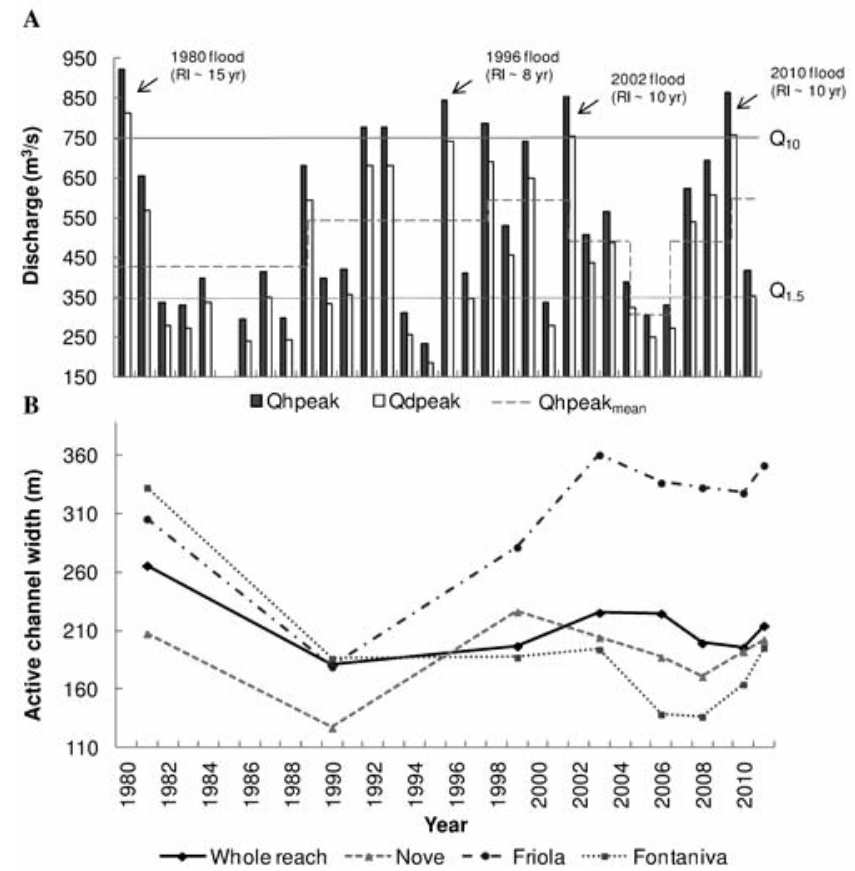

Figure 10. Time evolution of the average active channel width and RI of flood events. (A) Bar chart represents the maximum hourly discharge registered in the year (Qhpeak) and the maximum annual values of the mean daily water discharge (Qdpeak); Qhpeak $_{\text {mean }}$ represents the average of the annual Qhpeak over a period between two aerial photo-interpretations; (B) adjustments of the average active channel width. 
tions 2 to 5). Over the last five years, the upper sub-reach (except for section 1) has eroded large portions of floodplain, resulting in some channel incision as well. This fact seems to be related to the scarcity of sediment supply coming from the upstream reaches due to the low connectivity with the mountainous areas. In some portions of the uppermost sub-reach (e.g. section 2), the severe incision (up to $5 \mathrm{~m}$ ) has probably led to the formation of very coarse sub-layers. The bed appears to be remarkably well armoured (and possibly non completely alluvial), leading to a prevalent tendency of erosion that interests the banks rather than to further incise the channel. In the downstream reaches, where aggradation or equilibrium tendencies are dominant, the active channel is not widening and this is most likely due to two reasons: i) the longitudinal control works (built since the 1960s) that greatly reduce the possibility of lateral migration of the river; ii) mature riparian vegetation next to the active channel that stabilises the soil and reduce bank erosion.

\section{Are flood events the main driving factor affecting channel changes and island dynamics in the Brenta River?}

Looking at the multi-temporal analysis of the active channel width carried out using aerial photographs taken from 1981 to 2011, we can see a remarkable correspondence between widening trends of the active channel and the occurrence of flood events (Figure 10). If the lateral annual adjustment $\left(\mathrm{m}_{\text {year }}{ }^{-1}\right)$ is related to the average of annual hourly peak discharges at the Barzizza gauging station for the analysed photo-period, a directly proportional relationship emerges (Figure 11), showing that a stronger active channel widening corresponds to a higher magnitude of flooding. Active channel narrowing is clearly due to the expansion of riparian vegetation that establishes itself on floodplains and islands during periods in which there is little disturbance. Figure 11 shows that the points are fairly distributed along a line, except for the values referring to the period $2006-2008$, for which the relatively low average annual hourly values of peak discharge $\left(317 \mathrm{~m}^{3} \mathrm{~s}^{-1}\right)$ have not promoted any active channel narrowing. This fact might be explained if we consider that the lack of major flood events over a short period, such as in this case (2 years), can not be enough to create new stable sites for the development of woody vegetation. Edwards et al. (1999) noted that uprooted trees need suitable environmental conditions, such as the lack of flood events, to sprout and form pioneer islands. Subsequently, Gurnell et al. (2001), showed that lack of disturbance and availability of moisture are the most important factors that control the successful establishment of riparian trees. Large flood events provide the mechanisms by which wood and propagules are eroded, transported and deposited within the active channel. The interflood periods provide time for fine sediments and vegetation propagules to be redistributed by the wind. Even though the historical data series are quite reduced and do not allow advanced statistical analyses, a positive (though not significant $R=0.7 ; \mathrm{P}=0.08$ ) correlation between the adjustment rate of the active channel width $\left(\mathrm{m} \mathrm{year}^{-1}\right)$ and the average annual hourly peak discharge $\left(\mathrm{m}^{3} \mathrm{~s}^{-1}\right)$ was found at the reach scale over each considered period. At the reach scale, only floods with mean daily discharges (Qd) higher than $600 \mathrm{~m}^{3} \mathrm{~s}^{-1}$ (RI=5 years) were able to cause noticeable widening of the bankfull section $(>10 \mathrm{~m})$. Comiti et al. (2011) estimated that ten years represents the return interval of the peak discharge able to considerably modify the fluvial planimetric shape, especially of floodplains and islands. This is confirmed also by island reduction processes that take place due to flood events of considerable magnitudes (Comiti et al., 2011; Picco et al., 2012a, 2012b; Mao et al., 2012). Because of the importance of highmagnitude floods (RI>5 years) in shaping the river, a question arises

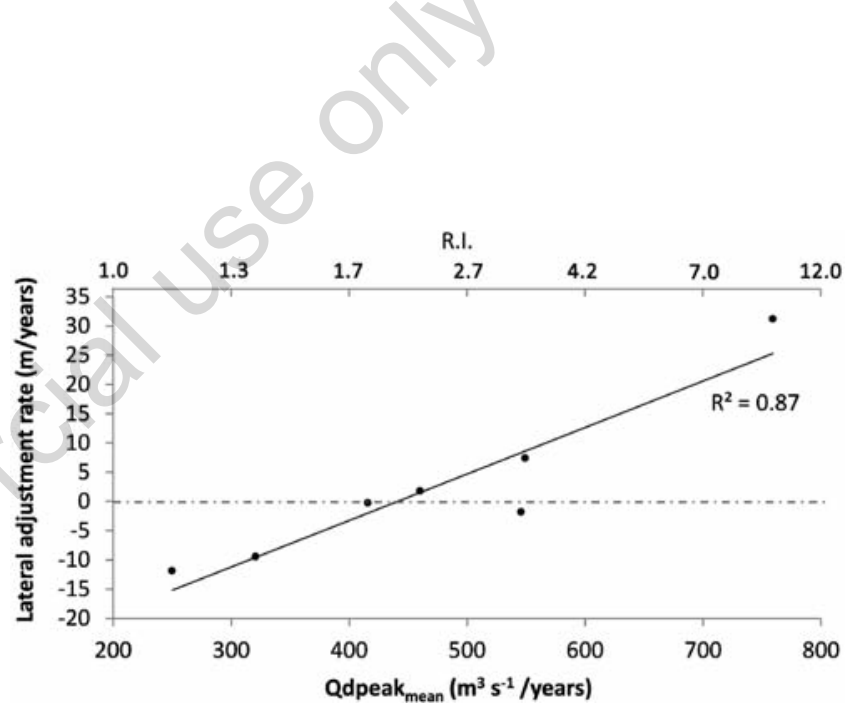

Figure 11. Rate of variation in active channel width $\left(\mathrm{m} \mathrm{year}^{-1}\right)$ in relation to the average annual daily peak discharge (Qdpeak $k_{\text {mean }}$ $\mathrm{m}^{3} \mathrm{~s}^{-1}$ ) over photo-periods and the corresponding recurrence interval.

Table 5. Amount of deposition and erosion in the different sub-reaches accounting for uncertainty. Standard uncertainty: $0.23 \mathrm{~m}$ Nove; 0.29 m Friola; 0.31 m Fontaniva.

\begin{tabular}{|c|c|c|c|c|c|c|}
\hline \multirow[b]{2}{*}{ DoD } & \multicolumn{3}{|c|}{ DoD changes } & \multicolumn{3}{|c|}{ Difference from original } \\
\hline & $\begin{array}{l}\text { Deposition } \\
\qquad\left(\mathrm{m}^{3}\right)\end{array}$ & $\begin{array}{c}\text { Erosion } \\
\left(\mathrm{m}^{3}\right)\end{array}$ & $\begin{array}{l}\text { Net } \\
\left(\mathrm{m}^{3}\right)\end{array}$ & $\begin{array}{c}\text { Deposition } \\
(\%)\end{array}$ & $\begin{array}{c}\text { Erosion } \\
(\%)\end{array}$ & $\begin{array}{l}\text { Total } \\
(\%)\end{array}$ \\
\hline \multicolumn{7}{|c|}{ No uncertainty analysis } \\
\hline Nove & 17,315 & 114,428 & $-97,113$ & NA & NA & NA \\
\hline Friola & 97,039 & 169,226 & $-72,187$ & NA & NA & NA \\
\hline Fontaniva & 95,376 & 110,994 & $-15,618$ & NA & NA & NA \\
\hline \multicolumn{7}{|c|}{ Standard uniform uncertainty } \\
\hline Nove & 9263 & 57,831 & $-48,568$ & -46.5 & -49.4 & -49.9 \\
\hline Friola & 53,359 & 113,404 & $-60,045$ & -45.0 & -32.9 & -16.8 \\
\hline Fontaniva & 55,494 & 74,062 & $-18,568$ & -41.8 & -33.2 & 18.8 \\
\hline
\end{tabular}

DoD, dem differencing model; NA, not available. 
as to the actual effectiveness of near-bankfull flows (RI 1.5 years) in determining the morphology of the Brenta River. Assuming that the dominant discharge is that which is more effective in transporting sediments in the long-term (Wolman and Miller, 1960; Andrews, 1980), it has previously been demonstrated that this often corresponds to the bankfull discharge (Andrews and Nankervis, 1995; Emmett and Wolman, 2001; Ferro and Porto, 2012). However, as suggested by Lenzi et al. (2006) who made a detailed analysis of the shaping effectiveness of bedload transporting floods in the Rio Cordon (Province of Belluno, north-eastern Italy), it seems likely that there are two dominant discharge ranges each with a distinct geomorphological effectiveness in the Brenta River: i) a relatively frequent near-bankfull flow range (RI 1.5 years) related to the bedload effective discharge, responsible for channel form maintenance; and ii) a more infrequent flow range (RI>10 years) responsible for macro-scale channel changes, such as channel width adjustment and stable island changes.

Despite the fact that natural channel adjustments at the reach level are mainly due to the occurrence of floods events, a fundamental role is also played by the individual characteristics of each sub-reach, which can strongly influence the change responses in the different portions of the river. From LiDAR surveys available for 2010 and 2011, accurate DTMs of the different sub-reaches were obtained, including the wetted portions of the channels (Moretto et al., 2012a, 2012b). The difference of DTM models (DoD) of the three sub-reaches, created by overlapping the 2010 and 2011 DTMs, have underlined a predominance of erosion processes due to the November and December 2010 flood events (Table 5). Interestingly, this erosion tendency tends to decrease going downstream. The difference between the amounts of erosion and deposition is higher (respectively $\sim 57,800 \mathrm{~m}^{3} v s \sim 9300 \mathrm{~m}^{3}$ ) and more concentrated in the uppermost sub-reach Nove. The difference then decreases towards the downstream sub-reaches: $113,400 \mathrm{~m}^{3}$ of erosion versus $\sim 53,400 \mathrm{~m}^{3}$ of deposition in Friola sub-reach and $\sim 74,000 \mathrm{~m}^{3}$ of erosion versus $\sim 55,500 \mathrm{~m}^{3}$ of deposition in Fontaniva sub-reach, respectively (Moretto et al., 2012a, 2012b). Table 5 shows also that a net pattern of change (deposition - erosion) is still present in Fontaniva $\left(-18,568 \mathrm{~m}^{3}\right)$ but that this is more pronounced and evident in the upstream subreaches of Nove $\left(-48,588 \mathrm{~m}^{3}\right)$ and Friola $\left(-60,045 \mathrm{~m}^{3}\right)$. Overall, differences in adjustment responses to the 2010-2011 flood events among the three sub-reaches could be linked to their different physical settings (especially bed slope), but also to the alteration in sediment flux and sediment availability from upstream reaches (Moretto et al., 2012a, 2012b; Rigon et al., 2012b). The higher erosion tendency in the first subreach Nove (Figure 12) might be due to the higher physical constraints that do not allow the channel to migrate. In fact, human structures aimed at protecting the nearby areas against floods (e.g. embankments, groins, and rip raps) seem to have reduced the active channel width, causing severe incision as partially confirmed by the recent multi-temporal analysis. The concentrated bank erosion could have been enhanced by both the alteration of sediment flux due to the low connectivity with the upstream drainage basin, and by the scarcity of vegetation growing on the banks. Sediment supply reaching the upstream subreach (Nove) is very low due to the presence of dams and torrent control systems in the mountain basin. As a result, there is virtually no connectivity with the upstream basin for bed-load and coarse sediment input to this sub-reach; so that transport capacity seems greater than sediment load input to the Nove sub-reach. Moreover, cross section 3, located at $\mathrm{km} 4.4$ (distance to section 1) in the longitudinal profile, represents a knick point in slope subjected to degradation, indicating that this part of the river is not entirely at equilibrium conditions. Erosion in the upper sub-reach Nove, above the knick point in slope, will continue until the slope is lowered sufficiently or the armour layer becomes fully developed (if sediment load input and bed load from the upstream basin do not increase in the future). In the Friola sub-reach, the channel has recently undergone a phase of stability and/or moderate recovery because since 1992-1994 there has been no further in-channel mining and significant bank erosion has recently occurred in the upstream sub-reach, supplying it with eroded sediments and coarse material. If the flow transport capacity has been filled by erosion of bed and bank sediments in the upper sub-reach, erosion will not affect cross section 6 , as confirmed by the evolution of the longitudinal bed profile between 2010 and 2012 (Figures 2 and 9). Thus, Friola sub-reach will be stable in the future and no or only little deposition can be expected (Rigon et al., 2012b). In the Fontaniva sub-reach, the higher amounts of deposition (if compared to the upper sub-reaches Nove and Friola) led to a near-equilibrium condition, with balanced erosion and deposition patterns. This could be due to the higher uniformity of this sub-reach and also to the higher degree of migration freedom of the river channel considering the fewer human structures and disturbances. In fact, past gravel mining activities were not intensive in this sub-reach, and enough volumes of coarse and fine sediments were available from bank erosion of the upper part of the study area. Moreover, the presence of vegetation and islands and the deposition enhancement caused by an artificially reduced bed slope, could have accounted for its substantial stability and less potential erosion. In this sense, the braiding morphological pattern and the stability trend is conserved in the short- and medium-term dynamics of this subreach. In most cases, erosion appears to affect lateral/bank areas of the river, but in the downstream sub-reaches, such as Fontaniva, the trend changes and erosion takes place in a more random fashion. Where there is less pressure from human intervention and the fluvial corridor is free of structural constraints, the river can expand laterally, resulting in a horizontal erosive shifting and a general widening of the channel. On the contrary, sub-reaches heavily constrained by human interventions or physical elements can suffer strong localised erosion processes, giving rise to vertical changes within the channel and representing, in most cases, a lower freedom environment for the river.

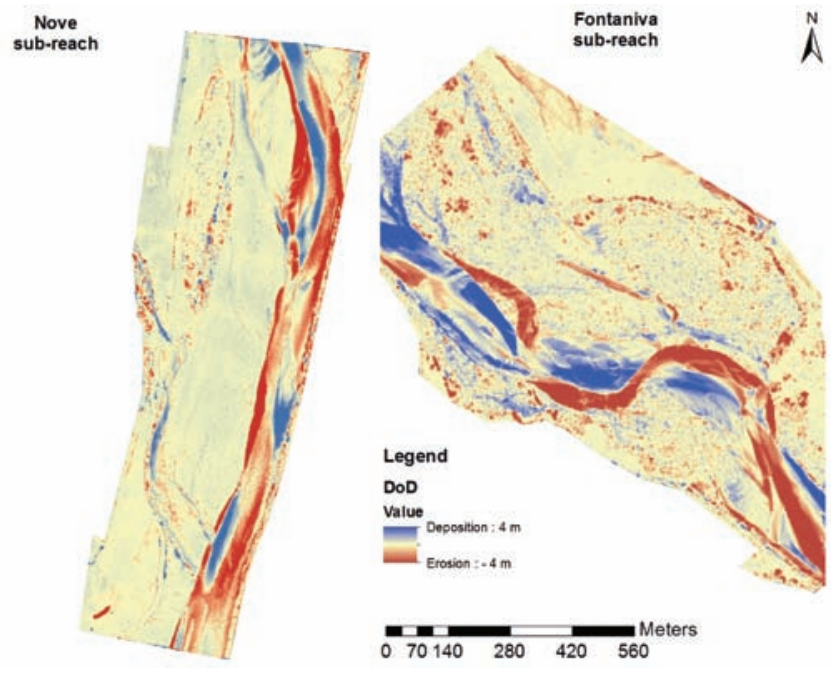

Figure 12. DEM differencing (DoD) models: variation in erosion and deposition trends of Nove and Fontaniva sub-reaches. 


\section{Dynamics of channel area and islands}

The dominance of erosion processes in the first sub-reach and a general stability and depositional phase on the third sub-reach are also reflected by the different island dynamics within the different subreaches. In the far downstream sub-reach (Fontaniva), sediment deposition and higher morphological stability create suitable conditions for the stabilisation of vegetation, while other active channel areas are more disturbed by floods and the islands are more affected by erosion processes. Besides these aspects, it is worth considering the relevant influence of direct human actions (e.g. vegetation removal, local clearcutting, bank protection, agricultural settlements, recreational areas) that are still present along the river corridor and can locally modify both morphological and vegetation dynamics (Picco et al., 2012a). The analysed fluvial system is the result of centuries of alterations, as highlighted for other rivers of the Veneto Region (Comiti $e t$ al., 2011). In the period 1990-2011, the fluvial dynamics of the Brenta River appears to have been less affected by human alterations, due particularly to the decrease in or virtual cessation of mining activities within the channel.

\section{Driving factors of channel evolution over the last 30 years and implications for channel recovery}

The study reach of the Brenta River was characterised by a period of strong narrowing of the active channel (from 1981 to 1990) followed by a general stability and an initial, light recovery phase (Figure 5). A similar situation was found in the Piave River (Comiti et al., 2011). Analysing this trend in detail, five periods can be identified (1981-1990, 1990-2003, 2003-2008, 2008-2010 and 2010-2011). Comparing the surface extension of the active channel at the beginning and at the end of each series, it was possible to highlight and calculate the erosion and deposition areas. Figure 5 reports enlargement and narrowing areas and the total areal variation in the active channel. In the first nine years (1981-1990), the active channel decreased by $\sim 225$ ha, equal to $19 \%$ of the total area, with a variation rate of 25 ha year ${ }^{-1}$ which represents the smallest historical extension. This period corresponds to a series of ordinary flood events (average annual hourly peak discharge $1981-1990=426 \mathrm{~m}^{3} \mathrm{~s}^{-1}$, maximum Qhpeak=682 $\mathrm{m}^{3} \mathrm{~s}^{-1}$ ) and a still significant human impact. The 1990s coincide with the end of the narrowing phase, commonly associated, for Italian rivers, to sediment mining activities. Some differences are noticeable with other Alpine regions where floodplain reforestation (following changes in the land use), along with sediment mining, is considered a major cause of channel erosion. As shown by the most recent channel evolution of the Brenta River, Rigon et al. (2012b) identified a phase of channel widening in several Italian rivers and Moretto et al. (2011) pointed out that this is often associated with aggradation, even if it can also occur without significant bed level changes. A similar phase in our study site can be recognised from 1990 to 2003. In this period, there was a partial recovery of the active channel width of $\sim 135$ ha (11\% of total area, 11 ha year $^{-1}$ ), probably due to flood events (e.g. 2002 and 1996) and/or a partial recovery of the natural fluvial dynamics (in relation to the reduction in gravel mining and pressure from human intervention). During these 12 years, in fact, we can observe an increase in the most intense flood events (average annual hourly peak discharge 1990-2003=572 $\mathrm{m}^{3}$ $\mathrm{s}^{-1}$, maximum Qhpeak 1990-2003=860 $\mathrm{m}^{3} \mathrm{~s}^{-1}$ and 6 floods with $\mathrm{RI} \geq 5$ year). During the third period (2003-2008), the trend changes once again as demonstrated by the multi-temporal analysis of the aerial photographs (Figures 5 and 8): the active channel surface decreases by $\sim 70$ ha (14 ha year ${ }^{-1}$ ) which corresponds to approximately $6 \%$ of the total area. In this period, flow intensity is reduced (average annual hourly peak discharge $2003-2008=425 \mathrm{~m}^{3} \mathrm{~s}^{-1}$, maximum Qhpeak 2003$2008=618 \mathrm{~m}^{3} \mathrm{~s}^{-1}$ ), and no flood events with RI over four years occur.
Observing the fourth period (2008-2010), we can observe a new small expansion of $10 \mathrm{ha}$, that corresponds to approximately $1 \%$, due to two subsequent floods of approximately $327 \mathrm{~m}^{3} \mathrm{~s}^{-1}$ (Qhpeak 2008) and 676 $\mathrm{m}^{3} \mathrm{~s}^{-1}$ (Qhpeak 2009). During the last, short, period (2010-2011) there was a consistent enlargement of approximately $41 \mathrm{ha}$, that correspond to approximately $3 \%$, due to the significant 2010 floods (Qhpeak=863 $\mathrm{m}^{3} \mathrm{~s}^{-1}$; Qdpeak $=759 \mathrm{~m}^{3} \mathrm{~s}^{-1}$ with $\mathrm{RI}=10$ years). In correspondence to this enlargement, a low channel incision in the upper part of the study reach is recognisable. On the contrary, in the second half of the reach, a relative phase of equilibrium or smooth aggradation can be distinguished. In contrast to the Piave River, where the most recent evolutions show a partial morphological recovery (Comiti et al., 2011), the dynamics highlighted in the Brenta River do not seem to show an effective revival towards more natural fluvial forms. Even though in the downstream area of Bassano del Grappa the cessation of mining activities has led to a decrease in erosion and narrowing processes starting from the early 1990s, a low morphological degradation of the river is still present. The main recognisable driving factors seem to be: i) extremely scarce availability of bed-load transported sediment from upstream; ii) absence of tributaries which can supply sediment; iii) larger bed-load transport capacity as a consequence of the slope increase registered since 1997 (+ 0.3\%). Downstream the active channel is much more stable, both in terms of width and elevation due to: i) greater availability of sediment from upstream as a consequence of bank and bed erosion; ii) lower slope ( $0.6 \%$ reduction) of the active channel with respect to 1997 from section 6 onwards; iii) greater presence of stable riparian vegetation; iv) reduction in sediment mobility carried out by numerous infrastructures such as bridges and dam structures (Carturo dam built in the 1970s). The recent variations of morphology and vegetation are related to the episodic severe flood events, in association with the effects of human intervention acting both on a reach (in the past) and basin (today) level.

The recent evolution (past thirty years) of the Brenta River in the study reach shows a deficit of sediment supply from the upstream river basin. The changes in the management of granting permission for gravel mining in the riverbed are reflected in the partial morphological recovery (active channel aggradation) in the final portion of the study reach. In order to avoid the adverse effects associated with the morphological deterioration experienced by the river in the past, it seems that the management strategy should pursue channel aggradation and promote bankfull expansion. These objectives could be achieved through a proper management of sediment with measures directed towards: i) preventing the extraction of gravel from the active channel and, if possible, locating these activities upstream of the dams, favouring the transfer downstream of trapped sediment in the reservoir; ii) a re-evaluation of torrent control measures, promoting open check dams with hydrodynamic filtering mechanism; iii) promoting the formation of an erodible river corridor, avoiding occupying areas within the levees with historical structures or agricultural activities; iv) a return to forest management in mountainous areas to promote recruitment processes of sediment from the slope. The modest recovery that the Brenta River is experiencing, especially in the second half of the downstream reach, can only continue and increase if the events and interventions described above are successfully integrated.

\section{Conclusions}

The medium- and short-term dynamics of morphological pattern, channel width, channel slope and islands of the study reach of the Brenta River are remarkably complex. This is due to the occurrence of spatially variable natural processes and human disturbance. During the 
study period, a widening phase of the active channel was observed with a reduction in island extension from 1990 to 2003 and from 2008 to 2011. On the other hand, from 1981 to 1990 and from 2003 to 2008 the river experienced channel narrowing and island expansion. However, considering the relevant spatial variability of morphological patterns, slope and the extent of human structures and disturbance, these dynamics and temporal trends differ greatly along the study reach. These processes have caused a different morphological evolution at the sub-reach level in terms of channel width and island extension. Other consequences concern channel slope that has shown an increase in the upper portion from 0.00495 to 0.00526 and a decrease in the lower portion of the study reach from 0.00429 to 0.00374 . Overall, it seems that the evolutionary trends of the sub-reaches depend on the sediment supply from upstream and the types and degree of local human disturbance and infrastructures. The analysis of aerial photographs, and especially the short-term channel evolution obtained by comparing recent LiDAR data (2010-2011), has revealed that the active channel is widening in the lower portion of the study reach where there is relatively little pressure from human intervention and there is still space along the fluvial corridor for the river to expand laterally. On the contrary, sub-reaches heavily constrained by human intervention or physical elements have suffered strong localised erosion processes and incision.

The initial hypotheses are only partially confirmed: i) planform and vertical correlation in the medium term (last thirty years) are different than in the long term, and in the upper part of the Brenta River, the analysed incision is not linked to expansion; ii) alteration on sediment supply that leads to recent channel and island changes is related to the extraction of sediment. Indeed, after the cessation of mining activities in the river channel ('90s), the Brenta River has partially recovered its morphology. However, this trend is not yet stable and not distributed along the entire study reach. In the upstream area, there are still incision and widening processes of the active channel as a result of bank erosion; iii) recent changes in the active channel dimension of the sub-reaches are related to the rates of flood events. The high-resolution analysis derived from LiDAR surveys, and DoD models, have represented a significant contribution to the definition of erosion-sedimentation patterns and to the evaluation of short-term morphological responses at sub-reach level. This analysis highlights that severe flood events ( $\mathrm{RI}>10$ years) cause substantial morphological modifications and erosion tends to decrease along downstream reaches. A more detailed and attentive assessment of sediment budget, to be compared with field measurements of sediment transport, is currently in progress and will be part of a future publication.

This study suggests that restoration strategies could enhance channel recovery, but their effectiveness will likely depend on the local impact of human intervention and sediment availability from upstream reaches. The upper sub-reach (Nove) is characterised by a very low sediment supply from upstream due to a transversal barrier and by numerous longitudinal defences that will prevent natural widening and recovery processes. Moreover, the region at the knick point in slope still shows a small degradation, indicating that this part of the river is not entirely at equilibrium conditions. On the contrary, the lower sub-reach (Fontaniva), is already widening and aggrading due to sediment supply from the upper and middle reaches, the stabilisation of the bed slope and the lower pressure from human intervention. Thus, in this case, restoration strategies (e.g. elimination of bank defences) will probably reinforce these natural tendencies.

\section{References}

Andrews E.D. 1980. Effective and bankfull discharges of streams in the Yampa River basin, Colorado and Wyoming. J. Hydrol. 46:311-30.
Andrews E.D. Nankervis J.M. 1995. Effective discharge and the design of channel maintenance flows for gravel-bed rivers. In: J.E. Costa et al., (eds.) Natural and anthropogenic influences in fluvial geomorphology, Geophys. Monogr. Ser., vol. 89, American Geophysical Union, Washington, DC, USA, pp 151-164.

Bathurst J.C., Crosta G., Garcìa-Ruiz J.M., Guzzetti F., Lenzi M., Rìos S. 2003. DAMOCLES: debrisfall assessment in mountain catchments for local end-users. In: Rickenmann D., Chen CL. (eds.) Proc. 3rd Intl. Conf. Debris-Flow Hazards Mitigation: Mechanics, Prediction and Assessment. Millpress, Rotterdam, the Netherlands, 2:10731083.

Braatne J.H., Rood S.B., Simons R.K., Gom L.A., Canali G.E. 2003. Ecology of riparian vegetation of the Hells Canyon corridor of the Snake River: field data, analysis and modeling of plant responses to inundation and regulated flows. Technical Report Appendix E. 3:33. Idaho Power Company. Boise, Idaho, USA.

Brasington J., Langham J., Rumsby B. 2003. Methodological sensitivity of morphometric estimates of coarse fluvial sediment transport. Geomorphology 53:299-316.

Comiti F., Da Canal M., Surian N., Mao L., Picco L., Lenzi M.A. 2011. Channel adjustments and vegetation cover dynamics in a large gravel bed river over the last 200 years. Geomorphology 125:147-59.

Edwards P.J., Kollmann J., Gurnell A.M., Petts G.E., Tockner K., Ward J.V. 1999. A conceptual model of vegetation dynamics on gravel bars of a large Alpine river. Wetlands Ecol. Manage. 7:141-53.

Emmett W.W., Wolman M.G. 2001. Effective discharge and gravel-bed rivers. Earth Surf. Proc. Landf. 26:1369-80.

Ferro V., Porto P. 2012. Identifying a dominant discharge for natural rivers in southern Italy. Geomorphology 139-140:313-21.

Giuliacci M., Abelli S., Dipierro G. 2001. Il clima dell'Italia nell'ultimo ventennio. Alpha test, Milano, Italy, p 344.

Gurnell A.M., Petts G.E. 2002. Island-dominated landscapes of large floodplain rivers, a European perspective. Freshwater Biol. 47:581600 .

Gurnell A.M., Petts G.E., Hannah D.M., Smith B.P.G., Edwards P.J., Kollmann J., Ward J.V., Tockner K. 2001. Riparian vegetation and island formation along the gravel-bed Fiume Tagliamento, Italy. Earth Surf. Proc. Landf. 26:31-62.

Gurnell A., Surian N., Zanoni L. 2009. Multi-thread river channels: a perspective on changing European alpine river systems. Aquatic Sci. 71:253-65.

Hicks D.M., Duncan M.J., Shankar U., Wild M. Walsh J.R. 2003. Project Aqua: lower Waitaki River geomorphology and sediment transport, NIWA Report CHC01/115, NIWA Research Center, Christchurch, New Zealand.

Kaless G., Mao L., Lenzi M.A. 2011. Regime theories in gravel bed rivers; preliminary comparison between disturbed rivers due to antrophic activities (Northeastern Italy) and natural rivers (Patagonia, Argentina). Proc. Int. Congr. AIIA, September 22-24, 2011, Belgirate (VB), Italy, p 8.

Kondolf G.M. 1997. Hungry water: effects of dams and gravel mining on river channels. Environ. Mgmt. 21:533-51.

Legleiter C.J. 2012. Remote measurement of river morphology via fusion of LiDAR topography and spectrally based bathymetry. Earth Surf. Proc. Landf. 37:449-518.

Lenzi M.A. 2006. Research developments in debris flow monitoring, modeling and hazard assessment in Italian mountain catchments. WIT Trans. Ecol. Environ. 90:135-45.

Lenzi M.A., D’Agostino V., Gregoretti C., Sonda D. 2003. A simplified numerical model for debris-flow hazard assessment: DEFLIMO. In: Rickenmann D., Chen CL. (eds.) Proc. 3rd Intl. Conf. Debris-Flow Hazards Mitigation: Mechanics, Prediction and Assessment. Millpress, Rotterdam, the Netherlands, 2:611-622. 
Lenzi M.A., Mao L., Comiti F. 2006. Effective discharge for sediment transport in a mountain river: computational approaches and geomorphic effectiveness. J. Hydrol. 326:257-76.

Liébault F., Piégay H. 2002. Causes of 20th century channel narrowing in mountain and piedmont rivers of southeastern France. Earth Surf. Proc. Landf. 27:425-44.

Mao L., Comiti F., Andreoli A., Lenzi MA., Scussel G.R. 2005. Bankfull and bed load effective discharge in a steep boulder-bed channel. IAHS Public. 291:189-95.

Mao L., Lenzi M.A. 2007. Sediment mobility and bed load transport conditions in alpine streams. Hydrol. Proc. 21:1882-91.

Mao L., Ravazzolo D., Picco L., Rigon E., Lenzi M.A. 2012. Types and volume of in-channel wood in three Italian gravel bed rivers suffering from different degrees of human disturbances. Proc. Int. Conf. Integrative Sciences and Sustainable Development of Rivers, June 26-28, Lyon, France, p 3.

Moretto J. 2010. Caratterizzazione dei fiumi ghiaiosi naturali ed antropizzati e analisi delle modificazioni morfologiche più recenti del Fiume Brenta tra Bassano del Grappa e Carturo. Degree Diss., University of Padova, Padova, Italy.

Moretto J., Delai F., Rigon E., Picco L., Mao L., Lenzi M.A. 2012a. Assessing short term erosion-deposition processes of the Brenta River using LiDAR surveys. WIT Trans. Eng. Sci. 73:149-60.

Moretto J., Rigon E., Lenzi M.A. 2011. Dinamica evolutiva di medio e breve termine della vegetazione riparia e della morfologia d'alveo del F. Brenta. Proc. of the Intern. Congress of the Italian AIIA, September 22-24, 2011, Belgirate (VB), Italy, pp 1-6.

Moretto J., Rigon E., Mao L., Delai F., Picco L., Lenzi M.A. 2012b. Assessing morphological changes in gravel bed rivers using LiDAR data and colour bathymetry. IAHS Public. 356:419-27.

Mount N.J., Louis J., Teeuw R.M., Zukowskyj P.M., Stott T. 2003. Estimation of error in bank full width comparison from temporally sequenced and corrected aerial photographs. Geomorphology 56:65-77.

Picco L., Mao L., Rigon E., Moretto J., Ravazzolo D., Delai F., Lenzi M.A. 2012a. Medium term fluvial island evolution in relation with flood events in the Piave River. WIT Trans. Engine. Sci. 73:161-72.

Picco L., Mao L., Rigon E., Moretto J., Ravazzolo D., Delai F., Lenzi M.A. 2012b. Riparian forest structure, vegetation cover and flood events in the Piave River. WIT Trans. Engine. Sci. 73:137-47.

Piégay H., Grant G., Nakamura F. and Trustrum N. 2006. Braided rivers management: from assessment of river behavior to improved sustainable development. IAHS Public. 36:257-75.

Poff N.L., Olden J.D., Merritt D.M., Pepin D.M. 2007. Homogenization of regional river dynamics by dams and global biodiversity implications. Proc. Natl. Acad. Sci. 104:5732-7.

Rickenmann D., D’Agostino V., Dalla Fontana G., Lenzi M.A., Marchi L. 1998. New results from sediment transport measurements in two Alpine torrents. IAHS Public. 248:283-9.

Rigon E., Comiti F., Lenzi M.A. 2012a. Large wood storage in streams of the Eastern Italian Alps and the relevance of hill slope processes. Water Resour. Res. 48:W01518.

Rigon E., Comiti F., Mao L., Lenzi M.A. 2008. Relationships among basin area, sediment transport mechanisms and wood storage in mountain basins of the Dolomites (Italian Alps). WIT Trans. Engine. Sci. 60:163-72.

Rigon E., Moretto J., Mao L., Picco L., Delai F., Ravazzolo D., Lenzi M.A., Kaless G. 2012b. Thirty years of vegetation cover dynamics and planforms changes in the Brenta River (Italy): implications for channel recovery. IAHS Public. 356:178-86.

Segato M., Mao L., Coccato M., Lenzi M.A., D’Agostino V. 2006. Operative approaches for debris flow modeling and hazard assessment, Laures watershed, Italy. WIT Trans. Ecol. Environ. 90:171-9.

Simonetto A. 2010. Caratteristiche morfologiche di alcuni fiumi ghiaiosi antropizzati e naturali e studio della stabilità del fiume Brenta tra Bassano e Carturo. Degree Diss., University of Padova, Padova, Italy.

Ward J.V., Tockner K., Edwards P.J., Kollmann J., Bretschko G., Gurnell A.M., Petts G.E., Rossaro B. 1999. A reference river system for the Alps: the Fiume Tagliamento. Regul. Rivers Res. Manage. 15:63-75.

Wolman M.G., Miller J.P. 1960. Magnitude and frequency of geomorphic processes. J. Geol. 68:57-74. 